\title{
Block Copolymers of Poly(L-lactide) and Poly( $\varepsilon$ - caprolactone) or Poly(ethylene glycol) Prepared by Reactive Extrusion
}

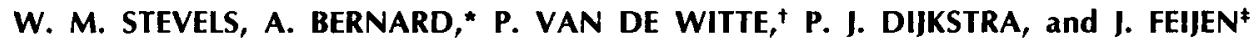 \\ Department of Chemical Technology and Institute for Biomedical Technology, BMTi, University of Twente, \\ P.O. Box 217, 7500 AE Enschede, The Netherlands
}

\begin{abstract}
SYNOPSIS
Blends of poly(L-lactide) (PLLA) and poly( $\varepsilon$-caprolactone) (PCL) were prepared in a corotating twin screw miniextruder $\left(40 \mathrm{rpm}, 200^{\circ}\right)$. It was attempted to prepare multiblock copolymers by allowing a controlled number of transesterification reactions. Various catalysts $\left(n-\mathrm{Bu}_{3} \mathrm{SnOMe}, \mathrm{Sn}(\mathrm{Oct})_{2}, \mathrm{Ti}(\mathrm{OBu})_{4}, \mathrm{Y}(\mathrm{Oct})_{3}\right.$, para-toluene sulphonic acid) were introduced to promote these transesterification reactions. However, PLLA degradation by ring-closing depolymerization was the dominant reaction in every case. Alternatively, after showing that L-lactide can be conveniently polymerized in the extruder, L-lactide and hydroxyl functionalized prepolymers of PCL or poly(ethylene glycol) (PEG) were fed to the extruder in the presence of stannous octoate. Monomer conversions of over $90 \%$ and effective transformation of all hydroxyl end groups present were generally reached. Di- and triblock copolymers could be prepared in this way with characteristics very similar to polymers prepared in a batch-type process, but with considerably reduced reaction times in a fashion, which is, in principle, scaleable to a continuous process for the production of such block copolymers. (C) 1996 John Wiley \& Sons, Inc.
\end{abstract}

\section{INTRODUCTION}

In the field of biodegradable and biomedical pciymers poly (lactide) (PLLA) is one of the most intensively studied polymers both in fundamental as well as in application directed research, because of its favourable properties. ${ }^{1-3}$ These properties include, for example, good biodegradability and high tensile strength. However, to further improve some properties such as impact strength, permeability, and hydrophilicity, copolymers of PLLA have been developed. Among these, the copolymers of lactide with glycolide, $\varepsilon$-caprolactone and ethylene glycol are the ones most frequently encountered. Many ways of

* Present address: Institute for Agrotechnological Research (ATO-DLO), P.O. Box 17, 6700 AA, Wageningen, The Netherlands.

${ }^{\dagger}$ Present address: Philips Research, Prof. Holstlaan 4, 5656 AA Eindhoven, The Netherlands.

$\ddagger$ To whom correspondence should be addressed.

Journal of Applied Polymer Science, Vol. 62, 1295-1301 (1996)

(C) 1996 John Wiley \& Sons, Inc. $\quad$ CCC 0021-8995/96/081295-07 producing such copolymers have been described, but invariable the methods were based on a batch-type operation, typically melt copolymerization. ${ }^{4}$ These melt polymerizations are usually carried out at temperatures below the melting temperature of PLLA, because at and above the melting temperature $\left(180^{\circ} \mathrm{C}\right)$ side reactions, such as racemization and ring-closing depolymerization, occur. ${ }^{5}$ This is very detrimental to the mechanical properties of PLLA. The lower temperatures used inevitably result in crystallization of PLLA, and, thus, to inadequate mixing, and in long reaction times. To make these copolymers available on a commercial scale the use of a continuous process would certainly be desirably and economically beneficial.

Transesterification is a well-known process for polyesters, and the process has been extensively investigated for blends containing poly(ethylene terephthalate) or poly(butylene terephthalate).$^{6-9}$ Examples in which transesterification is studied in blends containing purely aliphatic polyesters are relatively rare ${ }^{10}$ In contrast, the preparation of block 
or block type copolymers has received much attention, because the additivity of the phase properties allows easy modification of the polymer properties. The preparation of these block type copolymers could, in principle, be achieved by blending of the homopolymers and allowing a limited number of transesterification reactions. This possibility was investigated for blends of PCL and PLLA.

Two approaches were evaluated. In the first approach the feasibility of preparing multiblock copolymers by reactive blending of commercially available polymers was studied. In the second approach, it was attempted to prepare block copolymers by polymerizing the monomer L27-lactide in an extruder, with hydroxyl terminated prepolymers acting as initiators. The block copolymers prepared can be used as such, or be used to increase the compatibility of the polymer phases in related blends.

\section{EXPERIMENTAL}

\section{Materials}

Poly(L(-)-lactide) (Purac Biochem b.v., the Netherlands) $\left(\bar{M}_{n}=70,000, \bar{M}_{w} / \bar{M}_{n}=3.2\right)$, poly( $\varepsilon$-caprolactone) (Contivema, Rotterdam, The Netherlands) $\left(\bar{M}_{n}=55,000, \bar{M}_{w} / \bar{M}_{n}=1.2\right)$ and poly( $\varepsilon$-caprolactone) (Aldrich, Brussels, Belgium) (diol, $\bar{M}_{w}$ $=2000$ (producer), $\bar{M}_{n}=1500$ (as determined by ${ }^{1} \mathrm{H}$ NMR end group analysis) were used as received, poly (ethylene glycol) (Merck-Schuchardt, Darmstadt, Germany) (diol, $\left.M_{n}=2000\right)$. Ti $(\mathrm{OBu})_{4}$ (Ald-

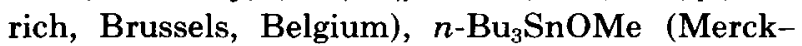
Schuchardt), Sn(Oct) ${ }_{2}$ (Sigma Chemical Co., St. Louis, MO) (Oct $=$ 2-ethylhexanoate), $\mathrm{Y}(\text { Oct })_{3}$ (Aldrich), para-tolene sulphonic acid (Merck-Schuchardt), $\mathrm{ZnCl}_{2}$ (Aldrich) were used as received. Trifluoroacetic anhydride (Aldrich) and chloroform- $d_{1}$ (Merck-Schuchardt) were used as received. Diphenylether (Merck-Schuchardt) was distilled from sodium prior to use.

\section{Characterization}

${ }^{1} \mathrm{H}-\mathrm{NMR}$ and ${ }^{13} \mathrm{C}$-NMR spectra were recorded on a Bruker AC 250 operating at $250 \mathrm{MHz}\left({ }^{1} \mathrm{H}\right)$ or 62.5 $\mathrm{MHz}\left({ }^{13} \mathrm{C}\right)$. XRF measurements were carried out on a Philips PW $1480 \mathrm{x}$-ray spectrometer, calibrated with $\mathrm{Li}_{2} \mathrm{~B}_{4} \mathrm{O}_{7}$, on films of PCL and PLLA. Gel permeation chromatography (GPC) was used to determine molecular weights and molecular weight distributions $\left(\bar{M}_{w} / \bar{M}_{n}\right)$. A Waters $6000 \AA$ GPC apparatus equipped with three Waters mStyragel $\left(10,{ }^{3}\right.$ $10,{ }^{4} 10^{5} \AA$ pore diameter) columns was used, combined with a $\mathrm{H} 502$ viscometer detector (Viscotek Corp.) for determination of absolute values of molecular weights. Polymers were dissolved in chloroform $(1.0 \mathrm{wt} \%)$ and elution was performed at $25^{\circ} \mathrm{C}$ at a flow rate of $2.0 \mathrm{~mL} / \mathrm{min}$ using chloroform as eluent.

$\mathrm{X}$-ray fluorescence spectrometry (XRF) was carried out on a Philips PW $\mathrm{x}$-ray spectrometer. Quantitave measurements were carried out using $\mathrm{Li}_{2} \mathrm{~B}_{4} \mathrm{O}_{7}$ calibration. Thermal analysis of polymers was carried out with a Perkin-Elmer DSC7 differential scanning calorimeter calibrated with pure indium. The polymers were heated from -20 to $220^{\circ} \mathrm{C}$ at a heating rate of $20^{\circ} \mathrm{C} / \mathrm{min}$.

\section{Extrusion}

Blending was performed in a small scale corotating twin screw extruder, developed by DSM N.V. (Geleen, the Netherlands) with a screw length of $12 \mathrm{~cm}$ and a capacity of about $4 \mathrm{~g}$ of polymer. The extruder was provided with a heated channel through which the polymer could be fed back. Polymers were extruded at a screw speed of $40 \mathrm{rpm}$ with a residence time of $5 \mathrm{~min}$. If PLLA was fed to the extruder the temperature was $200^{\circ} \mathrm{C}$, if L-lactide was fed to the extruder the temperature was $180^{\circ} \mathrm{C}$. Catalyst was added as a $20 \mathrm{wt} \%$ solution in toluene simultaneously with polymer or monomer. The extrudate was cooled in water and cut in pieces.
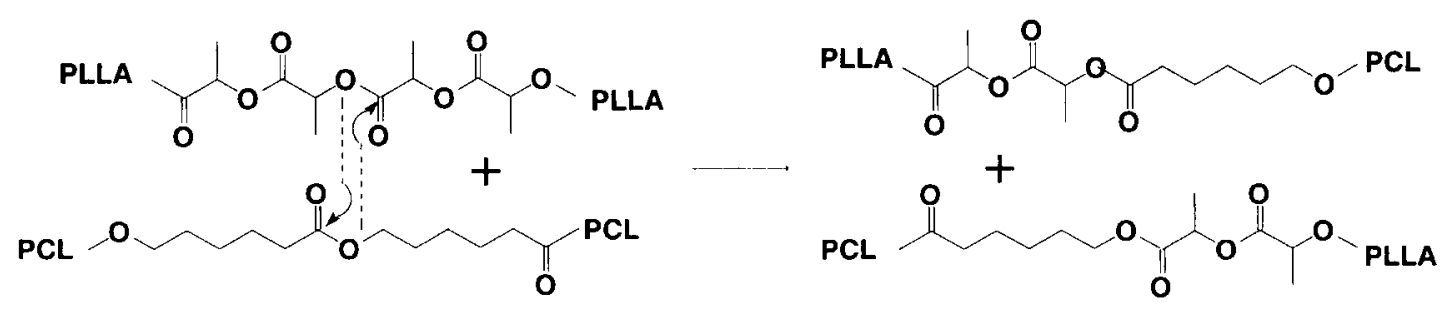

Figure 1 Transesterification of PCL and PLLA leading to a multiblock copolymer. 
Table I Results of Coextrusion of PLLA and PCL (50/50 by Weight) at $200^{\circ} \mathrm{C}, 40 \mathrm{rpm}$, and a Residence Time of 5 Minutes in the Presence of Various Catalysts ${ }^{a}$

\begin{tabular}{clccc}
\hline No. & Catalyst & $\begin{array}{c}\text { Amount } \\
(\text { wt \%) }\end{array}$ & $\begin{array}{c}\text { Lactide } \\
\text { Formed (\%) }\end{array}$ & Transesterification $^{\mathrm{b}}$ \\
\hline 1 & - & & 0 & - \\
$2^{\mathrm{c}}$ & - & & 0 & - \\
3 & $\mathrm{Bu}_{3} \mathrm{SnOMe}$ & 0.5 & 2 & - \\
4 & $\mathrm{Bu}_{3} \mathrm{SnOMe}$ & 1.0 & 5 & - \\
5 & $\mathrm{Bu}_{3} \mathrm{SnOMe}$ & 2.0 & 12 & - \\
6 & $\mathrm{Ti}(\mathrm{OBu})_{4}$ & 0.5 & $<1$ & - \\
7 & $\mathrm{Ti}(\mathrm{OBu})_{4}$ & 1.0 & 3 & - \\
8 & $\mathrm{Sn}(\mathrm{Oct})_{2}$ & 0.5 & 3 & - \\
9 & $\mathrm{Y}(\mathrm{Oct})_{3}$ & 0.5 & 0 & - \\
10 & $p-\mathrm{TSA}$ & 0.5 & 0 & - \\
$11^{\mathrm{d}}$ & $\mathrm{Ti}(\mathrm{OBu})_{4}$ & 0.5 & $<1$ & - \\
$12^{\mathrm{d}}$ & $\mathrm{Ti}(\mathrm{OBu})_{4}$ & 1.0 & $<1$ & \\
\hline
\end{tabular}

${ }^{\mathrm{a}} M_{n, \mathrm{PLLA}}=70.000 ; M_{n, \mathrm{PCL}}=55.000$.

${ }^{\mathrm{b}}$ As determined by ${ }^{1} \mathrm{H}$ and ${ }^{13} \mathrm{C}$ NMR spectroscopy.

${ }^{c}$ Polymers mixed by coprecipitation before feeding to the extruder.

${ }^{\mathrm{d}}$ A PCL-diol with a $M_{n}$ of 1500 was used.

\section{RESULTS AND DISCUSSION}

\section{Transesterification of PLLA and PCL}

The feasibility of preparing multiblock copolymers was studied by reactive blending of commercially available polymers and allowing a limited number of transesterification reactions, as shown in Figure 1.

PLLA is a polymer with a relatively narrow processing window because ring-closing depolymerization of PLLA with the formation of lactide readily occurs even at temperatures close to the melting temperature. ${ }^{6}$ Also, the hydrolytic stability is rather limited. Therefore, the optimal conditions for the extrusion of the homopolymers in the absence of any added catalyst was investigated. For the high molecular weight PLLA used in this study a melting

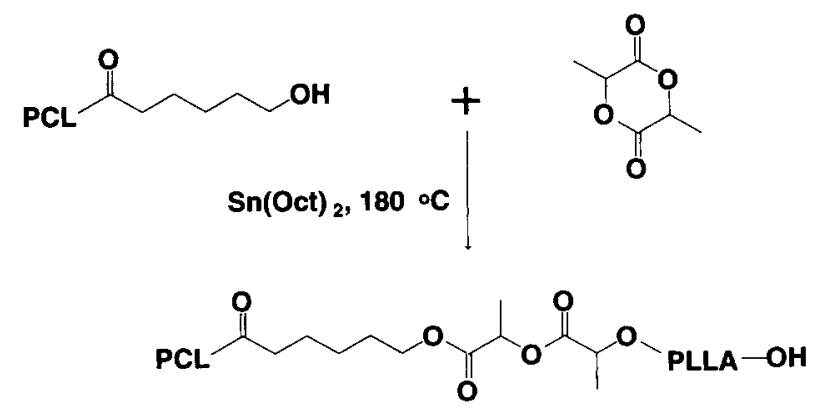

Figure 2 Polymerization of L-lactide initiated by a hydroxyl terminated PCL in the presence of stannous octoate. temperature of $186^{\circ} \mathrm{C}$ was determined by DSC. It was found that at a temperature of $200^{\circ} \mathrm{C}$, a screw speed of $40 \mathrm{rpm}$ and a residence time of $5 \mathrm{~min}$ only minor amounts of $\mathrm{L}$-lactide $(<1 \%)$ were formed and the remaining weight average molecular weight of the PLLA was still acceptable for the purpose of this study $(>100,000)$. Extrusion at lower temperatures was not feasible because the melt viscosity became too high. PCL is well known for its easy processability and, indeed, no depolymerization or reduction in the number average molecular weight was observed at any of the extrusion conditions evaluated. ${ }^{10}$

The presence of residual catalyst in the polymers used in this study (PLLA and PCL) could influence the results of this study and, therefore, the polymers were subjected to qualitative $\mathrm{x}$-ray fluorescence

Table II L-Lactide Homopolymerization Carried Out in a Miniextruder at $180^{\circ} \mathrm{C}, 40 \mathrm{rpm}$, and a Residence Time of 5 Minutes Using $\operatorname{Sn}(\text { Oct })_{2}$ at a Catalyst

\begin{tabular}{ccccc}
\hline No. & $\operatorname{Sn}(\text { Oct })_{2}$ & $\begin{array}{c}\text { Conversion } \\
(\%)\end{array}$ & $M_{n} * 10^{-3}$ & $M_{w} / M_{n}$ \\
\hline 1 & 0 & $<1$ & - & - \\
2 & 0.1 & 31 & 24 & 1.1 \\
3 & 0.25 & 68 & 35 & 1.2 \\
4 & 0.50 & 88 & 68 & 1.5 \\
5 & 1.0 & 93 & 43 & 1.5 \\
\hline
\end{tabular}


Table III Block Copolymer Synthesis by L-Lactide Polymerization Initiated by Hydroxyl Terminated Prepolymers of PCL and PEG, Carried Out in a Miniextruder at $180^{\circ} \mathrm{C}, 40 \mathrm{rpm}$, and a Residence Time of 5 Minutes in the Presence of 0.50 wt $\% \operatorname{Sn}(\text { Oct })_{2}$

\begin{tabular}{|c|c|c|c|c|c|c|}
\hline $\begin{array}{l}\text { No. } \\
\text { Prepolymers }^{\mathrm{a}}\end{array}$ & $\begin{array}{c}\text { Ratio L-Lactide/ } \\
\text { Prepolymer } \\
\text { (wt \%) }\end{array}$ & $\begin{array}{c}\text { Conversion } \\
(\%)\end{array}$ & $M_{n, \text { calc }}^{\mathrm{b}}$ & $M_{n, \mathrm{NMR}}$ & $M_{n, \mathrm{GPC}}$ & $M_{w} / M_{n}$ \\
\hline 1 PCK-I & $50 / 50$ & 90 & 2900 & 2700 & 5000 & 1.2 \\
\hline 2 PCL-I & $75 / 25$ & 94 & 5700 & 5600 & 7600 & 1.2 \\
\hline 3 PCL-I & $92.5 / 7.5$ & 96 & 19300 & 16500 & 21000 & 1.6 \\
\hline 4 PCL-II & $75 / 25$ & 92 & 22600 & 17600 & 17800 & 1.2 \\
\hline 5 PCL-II & $92.5 / 7.5$ & 91 & 73300 & 26000 & 33000 & 1.3 \\
\hline 6 PEG & $50 / 50$ & 98 & 3800 & 3600 & 3700 & 1.5 \\
\hline 7 PEG & $75 / 25$ & 96 & 7500 & 6000 & 8200 & 1.5 \\
\hline 8 PEG & $92.5 / 7.5$ & 96 & 25400 & 23300 & 25000 & 1.2 \\
\hline
\end{tabular}

${ }^{a}$ PCL-I: di-functional $\left(M_{n}=1500\right)$; PCL-II: monofunctional $\left(M_{n}=6000\right)$; PEG: di-functional $\left(M_{n}=2000\right)$.

${ }^{b}$ Calculated assuming every hydroxyl group initiates polymerization and corrected for conversion.

spectrometry (XRF) analysis. As the presence of tin was shown in both polymers, the amounts of this metal present in the polymers was determined. Values of 0.08 wt $\%$ and 0.001 wt \% tin in PLLA and PCL were found, respectively. When coextrusion of PLLA and PCL (Table I, entries 1-2) was carried out no transesterification nor lactide formation was observed and, thus, the amounts of catalysts present were too low to effectively promote the desired transformations.

Blends of PLLA and PCL ( $50 / 50$ by weight) were coextruded at $200^{\circ} \mathrm{C}$ and a screw speed of $40 \mathrm{rpm}$ in the presence of various transesterification catalysts. Results are shown in Table I (entries 3-10). The use of $n-\mathrm{Bu}_{3} \mathrm{SnOMe}$ was reported to catalyze the reaction between PLLA and PCL. If $2 \mathrm{wt} \%$ of $n$ - $\mathrm{Bu}_{3} \mathrm{SnOMe}$ was added to the blend some transesterification was observed, but also substantial PLLA degradation occurred as evidenced by the formation of relatively large amounts $(\sim 12 \mathrm{wt} \%)$ of L-lactide. Smaller amounts of $n$-Bu $\mathrm{Bu}_{3} \mathrm{SnOMe}$ were not effective in promoting transesterification under these reaction conditions. Therefore, we evaluated the use of the catalysts $\mathrm{Ti}(\mathrm{OBu})_{4}, \mathrm{Sn}(\mathrm{Oct})_{2}, \mathrm{Y}(\mathrm{Oct})_{3}$, and paratoluene sulphonic acid. All experiments revealed that no transesterification reactions occurred, and in all cases the PCL was recovered unchanged. PLLA degradation was observed as indicated by the formation of L-lactide and fast decrease in molecular weight.

In order to determine if alcoholysis may be used as a predominant reaction for the formation of block copolymers the poly(L-lactide) was mixed with a PCL-diol having a low molecular weight $\left(\bar{M}_{w}=2000\right)$ in the presence $\mathrm{Ti}(\mathrm{OBu})_{4}$, which is a well-known catalyst for this type of reaction from poly(ester) synthesis by polycondensation. The increased concentration of caproyl hydroxyl end groups, however, did not facilitate the formation of block copolymers (Table I, entries 11-12). Again, formation of L-lactide was observed in these experiments.

To determine whether the reaction time was too short for transesterification, a blend of PLLA and PCL was prepared by dissolving the polymer mixture in chloroform, addition of 2 wt $\% n$ $\mathrm{Bu}_{3} \mathrm{SnOMe}$, evaporation of the solvent, and heating the mixture to $150^{\circ} \mathrm{C}$ for $72 \mathrm{~h}$. A random copolyester of low molecular weight was obtained and large amounts of L-lactide were formed. ${ }^{11}$ The ${ }^{1} \mathrm{H}$ NMR spectra showed that the isolated polymer had methyl ester end groups as a result of the reaction of the catalyst. A similar experiment using $\mathrm{Ti}(\mathrm{OBu})_{4}$ as a transesterification catalyst left the polymers unchanged.

To exclude any effect of insufficient mixing, reactions were carried out in solution. Low molecular weight PLLA $\left(\bar{M}_{n}=10,000\right)$ and PCL $\left(\bar{M}_{n}=1500\right)$ were dissolved in diphenyl ether ( $10 \mathrm{wt} \%$ solution) and heated for $120 \mathrm{~h}$ at $170^{\circ} \mathrm{C}$ in the presence of 1 wt \% $\mathrm{Ti}(\mathrm{OBu})_{4}, \mathrm{Sn}(\mathrm{Oct})_{2}$, or $\mathrm{ZnCl}_{2}$. Whereas in the case of $\mathrm{Ti}(\mathrm{OBu})_{4}$ no reaction occurred, the other catalysts promoted the formation of block copolymers and some L-lactide. The ${ }^{1} \mathrm{H}$ NMR data showed that the block copolymers formed were triblock copolymers and not random copolymers. The end group analysis of such block copolymers has been discussed elsewhere ${ }^{15}$ and will not be discussed in detail here. ${ }^{1} \mathrm{H}-\mathrm{NMR}$ spectrum showed that the signal belonging to the $-\mathrm{CH}_{2} \mathrm{OH} \varepsilon$-caprolactone end group $(\delta=3.57)$ had disappeared and that signals 


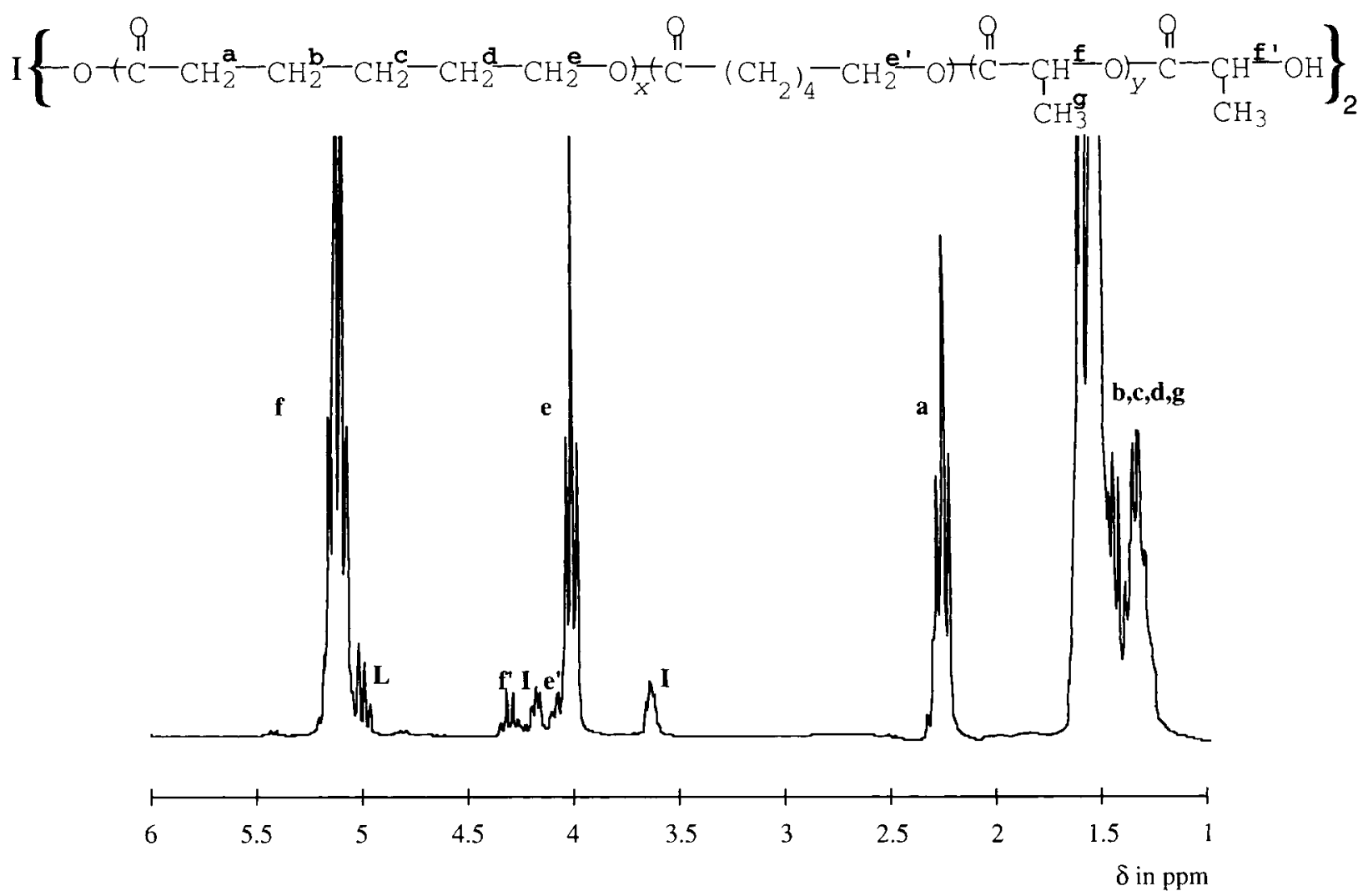

Figure $3 \quad{ }^{1} \mathrm{H}-\mathrm{NMR}$ spectrum of an as-polymerized triblock copolymer of PCL and PLLA prepared by polymerization of L-lactide initiated by a hydroxyl terminated PCL in the presence of stannous octoate (chloroform- $d_{1}$ ). Signals attributable to unreacted L-lactide are denoted "L" and of initiator fragments in the commercial prepolymer "I."

attributable to a $-\mathrm{CH}(\mathrm{CH})_{3} \mathrm{OH}(\delta=4.30,2.8)$ lactyl end group had appeared. Because $\mathrm{Sn}(\mathrm{Oct})_{2}$ is well known as an excellent catalyst for the polymerization of lactones, the results indicate that the formation of these diblock copolymers is only due to the depolymerization of PLLA to give L-lactide and subsequent ring-opening polymerization. The hydroxyl end group of the PCL chains acts as an initiator in the polymerization reaction.

Transesterification to afford multiblock copolymers is, thus, difficult to achieve under the different conditions used. Probably the stability of the ester bonds is too high at the temperatures used to effectively allow transesterification. A further elevation of the temperature leads to the depolymerization of the PLLA and will not allow the formation of multiblock copolymers.

\section{Polymerization of L-Lactide in an Extruder}

The experiments described suggested a second approach for the easy preparation of PLLA-PCL block copolymers. It is well known that alcohols are ef- fective coinitiators in the stannous octoate catalyzed polymerization of lactides. ${ }^{12-14}$ Hydroxyl-terminated prepolymers could be mixed with L-lactide and fed to the extruder in the presence of stannous octoate, as shown in Figure 2.

First, it was evaluated if L-lactide could be polymerized satisfactorily in the extruder in the presence of various amounts of $\mathrm{Sn}(\mathrm{Oct})_{2}$. Results are shown in Table II.

It is important to note that extrusion can now be performed at $180^{\circ} \mathrm{C}$, because it is no longer necessary to melt PLLA before it enters the extrusion zone. The melting point of the PLLA produced is depressed by the presence of low melting prepolymer or by the presence of residual monomer. Side reactions are less important at $180^{\circ} \mathrm{C}$, which is advantageous in many aspects. It was found that the monomer conversion increases with the amount of catalyst at the relatively short residence time of 5 min and that high conversions can be achieved. In the absence of $\mathrm{Sn}(\mathrm{Oct})_{2}$ polymerization of L-lactide did not occur. Furthermore, number average molecular weights of up to 68,000 could be reached, which 


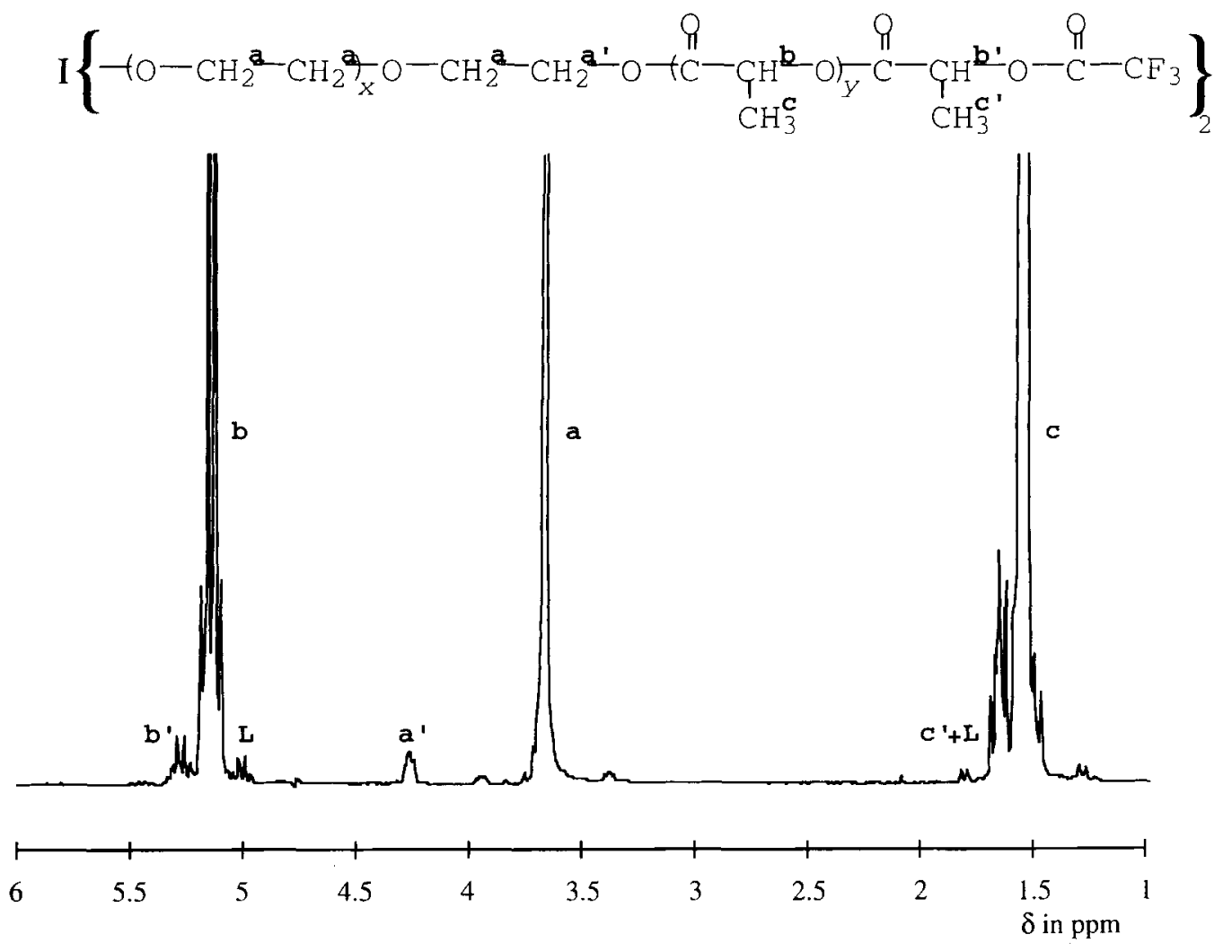

Figure $4{ }^{1}$ H-NMR spectrum of as-polymerized triblock copolymer of PEG and PLLA prepared by polymerization of L-lactide initiated by a hydroxyl terminated PEG in the presence of stannous octoate (chloroform- $d_{1}$ in the presence of $\mathrm{CF}_{3} \mathrm{C}(\mathrm{O}) \mathrm{OC}(\mathrm{O}) \mathrm{CF}_{3}$ ). Signals attributable to unreacted L-lactide are denoted " $L$."

is sufficiently high for most applications. It is observed that the molecular weight passes through a maximum with increasing catalyst concentration. In stannous octoate promoted polymerizations it is generally assumed that residual traces of water present in either catalyst or monomer are the actual initiators of the polymerization. With increasing amounts of catalyst the concentration of initiator is also increased and, thus, the molecular weight decreases.

In a next series of experiments, three different prepolymers were used as potential initiators: a PCL diol with a $\bar{M}_{n}$ of 1500 , a monofunctional PCL with a $\bar{M}_{n}$ of 6000 , and a poly(ethylene glycol) with a $\bar{M}_{n}$ of 2000. Results are shown in Table III.

Conversion of monomer was higher than $90 \%$ in all cases. NMR end group analysis showed that all hydroxyl end groups had initiated lactide polymerization and that block copolymers were formed with lactyl hydroxyl end groups. The end group analysis of such block copolymers has been discussed elsewhere ${ }^{15}$ and will not be discussed in detail. In the case of the PCL prepolymers, the ${ }^{1} \mathrm{H}-\mathrm{NMR}$ spectrum showed that the signal belonging to the - $\mathrm{CH}_{2} \mathrm{OH} \varepsilon$-caprolactone end group $(\delta=3.57)$ had disappeared and that signals attributable to a $-\mathrm{CH}(\mathrm{CH})_{3} \mathrm{OH}(\delta=4.30)$ lactyl end group have appeared, as shown in Figure 3.

Similarly, no unreacted PEG - $\mathrm{OH}$ end groups remained after reaction, as shown by ${ }^{1} \mathrm{H}-\mathrm{NMR}$ spectroscopy after preparation of the trifluoro acetic ester derivative of the polymers, as shown in Figure $4 .{ }^{16,17}$

Remarkably, number average molecular weights found by NMR end group analysis or by gel permeation chromatography were close to the values calculated from the monomer to hydroxyl group ratio. However, for the polymers with the highest calculated $\bar{M}_{n}$ s, lower $\bar{M}_{n}$ s are found. Most likely, homopolymerization of lactide occurs in these cases. ${ }^{4}$ It is of interest to note that the characteristics of the polymers prepared are very similar to 
polymers prepared in the melt, but now polymerization is complete within minutes instead of hours.

\section{CONCLUSIONS}

It was shown that the preparation of multiblock copolymers of PLLA and PCL by controlled transesterification reactions cannot effectively be performed in an extruder, primarily due to the small processing window of PLLA. However, di- and triblock copolymers are very effectively produced in high yield by coextrusion of L-lactide with hydroxyl terminated poly ( $\varepsilon$-caprolactone) and poly (ethylene glycol) under the influence of stannous octoate. This is a very promising method for the production of these copolymers in a continuous fashion with considerably reduced reaction times and without the use of any solvent.

These investigations were supported by the Netherlands Foundation for Chemical Research with financial aid from the Netherlands' Technology Foundation.

\section{REFERENCES}

1. H.-G. Fritz, T. Seidenstücker, U. Bölz, M. Juza, J. Schroeter, and H.-J. Endres, in Study on Production of Thermoplastics and Fibres Based Mainly on Biological Materials, Stuttgart, Germany, 1994, p. 113.
2. M. Vert, G. Schwarch, and J. Coudane, J. Mater. Sci., Pure Appl. Chem., A32, 787 (1995).

3. M. Vert, S. M. Li, G. Spenlehauer, and P. Guerin, $J$. Mater. Sci, Mater. Med., 3, 432(1992).

4. P. van de Witte, E. Velner, P. in't Veld, P. J. Dijkstra, and J. Feijen, J. Pol. Sci., Pol. Chem., to appear.

5. K. Jamshidi, S.-H. Hyon, and Y. Ikada, Polymer, 29, 2229 ( 1988).

6. A. M. Kotliar, J. Pol. Sci., Macromol. Rev., 16, 367 (1981).

7. R. S. Porter and L.-H. Wang, Polymer, 33, 2019 (1992).

8. G. Montaudo, M. S. Montaudo, E. Scamporrino, and D. Vitalini, Macromolecules, 25, 5099 (1992).

9. A. Legros, P. J. Carreau, B. D. Favis, and A. Michel, Polymer, 35, 758 (1994).

10. M. Nelissen, H. Keul, and H. Höcker, Macromol. Mol. Phys., 196, 1645 (1995).

11. H. R. Kricheldorf, I. Kreiser, J. Macromol. Sci. Chem., A24, 1345 (1987).

12. A. J. Nijenhuis, D. W. Grijpma, and A. J. Pennings, Macromolecules, 25, 6419 (1992).

13. X. Zhang, A. Macdonald, M. F. A. Goosen, and K. B. Mcauley, J. Pol. Sci., Pol. Chem., 32, 2965 (1994).

14. H. R. Kricheldorf, I. Kreiser-Saunders, and C. Boettcher, Polymer, 36, 1253 (1995).

15. W. M. Stevels, M. J. K. Ankoné, P. J. Dijkstra, and J. Feijen, Macromol. Chem. Phys., 196, 1153 (1995).

16. L. Youxin and T. Kissel, J. Control. Rel., 17, 247 (1993).

17. H. R. Kricheldorf and J. Meier-Haack, Makromol. Chem., 194, 715 (1993).

Received January 22, 1996

Accepted June 19, 1996 